Article

\title{
The Macrophage Migration Inhibitory Factor (MIF) Promoter Polymorphisms (rs3063368, rs755622) Predict Acute Kidney Injury and Death after Cardiac Surgery
}

\author{
Luisa Averdunk 1,2 (D), Jürgen Bernhagen ${ }^{3,4,5} \mathbb{D}$, Karl Fehnle ${ }^{6}$, Harald Surowy ${ }^{2}$, \\ Hermann-Josef Lüdecke ${ }^{2}$, Sören Mucha ${ }^{7,8}{ }^{\mathbb{D}}$, Patrick Meybohm ${ }^{9}$, Dagmar Wieczorek ${ }^{2}$, \\ Lin Leng ${ }^{10}\left(\mathbb{D}\right.$, Gernot Marx ${ }^{1}$, David E. Leaf ${ }^{11,12} \mathbb{( D}$, Alexander Zarbock ${ }^{13}$, Kai Zacharowski ${ }^{9}$ (D), \\ on behalf of the RIPHeart Study Collaborators ${ }^{\dagger}$, Richard Bucala ${ }^{10, *, \ddagger}$ and \\ Christian Stoppe ${ }^{1,14, *, \ddagger(D)}$
}

1 Department of Intensive Care Medicine, University Hospital Aachen, Rheinisch Westphälische Technische Hochschule Aachen, 52074 Aachen, Germany; luisa.aver@gmail.com (L.A.); gmarx@ukaachen.de (G.M.)

2 Institute of Human Genetics and Department of Pediatrics, Medical Faculty, Heinrich Heine University, 40225 Düsseldorf, Germany; harald.surowy@uni-duesseldorf.de (H.S.);

Hermann-Josef.Luedecke@uni-duesseldorf.de (H.-J.L.); dagmar.wieczorek@hhu.de (D.W.)

3 Department of Vascular Biology, Institute for Stroke and Dementia Research, Klinikum der Universität München, Ludwig-Maximilians-University Munich, 80333 Munich, Germany; Juergen.Bernhagen@med.uni-muenchen.de

4 German Center for Cardiovascular Research (DZHK), Partner Site Munich Heart Alliance, 10785 Berlin, Germany

5 Munich Cluster for Systems Neurology (EXC 2145 SyNergy), 81377 Munich, Germany

6 Algora: Statistics and Clinical Research GmbH, 85540 Haar, Germany; karl.fehnle@algora.de

7 Institute of Clinical Molecular Biology, Christian Albrechts University of Kiel, 24118 Kiel, Germany; s.mucha@ikmb.uni-kiel.de

8 Institute for Cardiogenetics, University of Lübeck, Ratzeburger Allee 160, 23562 Lübeck, Germany

9 Department of Anesthesiology, Intensive Care Medicine \& Pain Therapy, University Hospital Frankfurt, Goethe University, 60323 Frankfurt, Germany; meybohm_p@ukw.de (P.M.); kai.zacharowski@kgu.de (K.Z.)

10 Department of Internal Medicine, Yale University School of Medicine, New Haven, CT 06510, USA; lin.leng@yale.edu

11 Division of Renal Medicine, Brigham and Women's Hospital, Boston, MA 02115, USA; deleaf@bwh.harvard.edu

12 Harvard Medical School, Boston, MA 02115, USA

13 Intensive Care and Pain Medicine, Department of Anesthesiology, University of Münster, 48149 Münster, Germany; zarbock@uni-muenster.de

14 Department of Anesthesiology, Intensive Care Medicine and Pain Therapy, University Hospital Würzburg, 97080 Würzburg, Germany

* Correspondence: richard.bucala@yale.edu (R.B.); christian.stoppe@gmail.com (C.S.); Tel.: +49-241-8036575 (R.B. \& C.S.); Fax: +49-241-8082406 (R.B. \& C.S.)

+ RIPHeart Study Collaborators are listed at the end of the manuscript. See Supplemental Acknowledgments for consortium details.

$\ddagger$ Contributed equally as last authors.

Received: 3 August 2020; Accepted: 1 September 2020; Published: 11 September 2020 updates

Abstract: Background: Macrophage Migration Inhibitory Factor (MIF) is highly elevated after cardiac surgery and impacts the postoperative inflammation. The aim of this study was to analyze

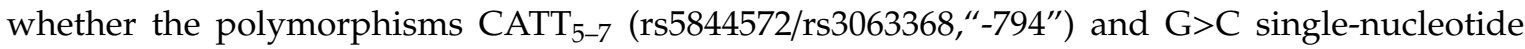
polymorphism (rs755622,-173) in the MIF gene promoter are related to postoperative outcome. Methods: In 1116 patients undergoing cardiac surgery, the MIF gene polymorphisms were analyzed and serum MIF was measured by ELISA in 100 patients. Results: Patients with at least one extended repeat allele $\left(\mathrm{CATT}_{7}\right)$ had a significantly higher risk of acute kidney injury (AKI) compared to 
others ( $23 \%$ vs. $13 \%$; OR $2.01(1.40-2.88), p=0.0001)$. Carriers of $\mathrm{CATT}_{7}$ were also at higher risk of death (1.8\% vs. $0.4 \%$; OR $5.12(0.99-33.14), p=0.026)$. The GC genotype was associated with AKI ( $20 \%$ vs. GG/CC:13\%, OR $1.71(1.20-2.43), p=0.003)$. Multivariate analyses identified CATT $_{7}$ predictive for AKI (OR 2.13 (1.46-3.09), $p<0.001$ ) and death (OR 5.58 (1.29-24.04), $p=0.021$ ). $\mathrm{CATT}_{7}$ was associated with higher serum MIF before surgery $(79.2 \mathrm{vs} .50 .4 \mathrm{ng} / \mathrm{mL}, p=0.008)$. Conclusion: The $\mathrm{CATT}_{7}$ allele associates with a higher risk of AKI and death after cardiac surgery, which might be related to chronically elevated serum MIF. Polymorphisms in the MIF gene may constitute a predisposition for postoperative complications and the assessment may improve risk stratification and therapeutic guidance.

Keywords: acute kidney injury; genetic polymorphisms; risk prediction; (cardiac) surgery; inflammatory cytokines; clinical studies

\section{Introduction}

Conventional open-heart surgery is performed annually in more than one million patients worldwide, and the incidence of postoperative sequelae including acute organ dysfunction remains high [1,2]. A more precise identification of patients' risk for postoperative complications is desirable both for prognostic guidance and for the application of earlier and more effective interventions. While clinical scoring systems such as the well-established EuroSCORE were primarily developed for the preoperative risk stratification of mortality in cardiac surgery patients, only limited evidence exists about its value for postoperative organ dysfunction and other complications [3]. The identification of genomic risk alleles could be especially helpful to more accurately predict outcomes and to enable personalized medicine approaches.

Oxidative stress and a systemic inflammatory response contribution to the pathogenesis of postoperative organ dysfunctions following cardiac surgery [4]. Macrophage migration inhibitory factor (MIF) is a stress-regulating cytokine that increases in the circulation after cardiac surgery [5]. Within the MIF gene promoter, two polymorphisms, a $\mathrm{G}>\mathrm{C}$ single nucleotide polymorphism 270 bases before MIF transcription start (-270) (originally described as -173; HGVS nomenclature: NM_002415.2 c. $-270 G>C$, rs755622) and a CATT tetranucleotide repeat CATT $_{5-7}$ (rs3063368), have been associated with disease severity of multiple chronic inflammatory diseases, including osteoporosis, ankylosing spondylitis, and multiple sclerosis [6-8]. A higher number of CATT repeats has been reported to increase MIF promotor activity and to be associated with higher circulating MIF concentrations in different autoimmune and chronic inflammatory conditions [9-12]. The clinical significance of functional polymorphisms in MIF for postoperative outcome after cardiac surgery is unknown. In this study, we analyzed 1116 patients who underwent elective cardiac surgery with a cardiopulmonary bypass. We analyzed whether MIF promoter polymorphisms impact the risk of postoperative organ dysfunction and mortality in patients undergoing cardiac surgery. In a subset of patients, we also examined the correlation between MIF genotypes and circulating MIF levels.

\section{Materials and Methods}

\subsection{Study Design and Patients}

The present study is a predefined sub-study performed in cardiac surgery patients of the Remote Ischemic Preconditioning Heart (RIPHeart) study (January 2011-May 2014), which investigated whether upper limb remote ischemic conditioning reduced mortality and the incidence of myocardial infarction, stroke, and acute kidney injury (AKI) in adults scheduled for elective cardiac surgery requiring a cardiopulmonary bypass [13]. As the initial intervention study did not show group differences, this MIF polymorphism study includes all patients irrespective of the initial group assignment [13]. The trial 
was undertaken in compliance with International Conference on Harmonisation Good Clinical Practice guidelines, the Declaration of Helsinki (2008), and European Directive 2001/20/CE regarding the conduct of clinical trials (4 April 2001). The study was registered at ClinicalTrials.gov (NCT01067703). The study protocol was approved by the ethics committees of the University of Kiel, Aachen, and all participating centers of this prospective multicenter study.

Patients scheduled for elective cardiac surgery with use of cardiopulmonary bypass (e.g., coronary artery bypass graft (CABG), valve surgery, ascending aorta replacement) were eligible for this study. Of the 1403 patients screened for the study, blood samples were available from 1196 patients. Seven patients were excluded due to missing outcome data and 70 patients were excluded due to missing genotype information (Supplemental Figure S1). Thus, data from 1119 patients were included in the current study. The $\mathrm{CATT}_{8}$ genotype was excluded from analysis because of its low frequency $(N=3)$, which is in accord with prior reports [14].

Blood samples were collected before surgery, at 45 min after cardiopulmonary bypass (CPB) initiation, at $2 \mathrm{~min}$ after opening of the cross-clamp (reperfusion), at $15 \mathrm{~min}$ after weaning from CPB, and at 1,6 , and $24 \mathrm{~h}$ after admission to ICU. Blood samples were processed no later than $2 \mathrm{~h}$ after collection and were stored at $-70^{\circ} \mathrm{C}$ or $-20^{\circ} \mathrm{C}$ until further transfer. The final study visit took place either before hospital discharge, or at the latest 30 days after ICU admission.

\subsection{Outcome Measures}

The primary exposure was the MIF genotype, which we analyzed according to the following groups: alleles (e.g., carriers of at least one $C$ allele), genotypes (e.g., GC), and individual genotype combinations (e.g., $\mathrm{CATT}_{5,7}-\mathrm{GC}$ ). The endpoints were the association between the MIF genotype and the incidence of postoperative organ dysfunctions, including AKI, myocardial infarction, new onset of atrial fibrillation, stroke, delirium, and death. Each of these outcome parameters were analyzed as single events, and in the composite outcome "multiple organ dysfunction", when patients suffered from more than one organ dysfunction.

According to the KDIGO Clinical Practice Guideline 2012, AKI was defined as a $\geq 5$-fold increase of serum creatinine from baseline, and a urine output of $\leq 0.5 \mathrm{~mL} / \mathrm{kg} / \mathrm{h}$ for more than $6 \mathrm{~h}$, or the use of renal replacement therapy within $72 \mathrm{~h}$ [15]. However, a total creatinine increase of $\geq 0.3 \mathrm{mg} / \mathrm{dL}$ was not considered a diagnostic criterion for AKI, as this criterion had not yet been established in 2011 when the data collection started. Non-fatal myocardial infarction was defined by biomarker values more than five times higher than the 99th percentile of the normal reference range combined with new pathological Q-waves or new left bundle branch block within the first $72 \mathrm{~h}$, standard clinical criteria for myocardial infarction from $72 \mathrm{~h}$ on, new ischemic finding by echocardiography or angiography, or myocardial infarction diagnosed at autopsy [16]. New onset of atrial fibrillation was defined as a new onset within the first four days after surgery [13]. The occurrence of postoperative delirium was assessed with the CAM-ICU score (preoperative, 24, 48, 72, and $96 \mathrm{~h}$ after surgery) [17]. Stroke was defined by any new, temporary or permanent, focal or global neurological deficit, or evidence of stroke on autopsy, and was evaluated according to the National Institutes of Health Stroke Scale ( $\geq 4$ points) [18].

Myocardial infarction, atrial fibrillation, and stroke were analyzed until hospital discharge with a maximum of 14 days after surgery.

\subsection{ELISA}

Serum was available from 100 patients in the RIPheart Study. Serum MIF levels were quantified by ELISA in duplicates as previously described and according to the manufacturer's instructions (R\&D Systems, Minneapolis, MN, USA) ([5]). Samples were diluted 1:10 before analysis to obtain measures in the valid assay range. 


\subsection{Nomenclature and Genotyping of the Tetranucleotide Repeat Polymorphism CATT ${ }_{n}$ (rs3063368)}

In adherence to the U.S. National Library of Medicine dbSNP database (ncbi.nlm.nih.gov/snp/), the tetranucleotide repeat polymorphism formerly described as rs5844572, referring to the $\mathrm{CATT}_{6}$ allele, will be referred to with the reference SNP number rs3063368, which comprises the multiallelic repeat polymorphism CATT $_{n}$ present at this site. The tetranucleotide repeat polymorphism is located at position chr22:23893566-23893569: (GRCh38.p12) (ncbi.nlm.nih.gov/snp/rs3063368), and based on older transcript annotations (NM_002415.2) -794 nucleotides, or based on more accurate transcript annotations (NM_002415.2) -909 nucleotides upstream of the start codon. The repeat polymorphism is a deletion, or respectively a duplication, of TTCA tetranucleotide repeats. In parallel with former publications, in this study this SNP will be referred to as a tetranucleotide 5-, 6-, 7-, or 8- fold repeat of CATT. The DNA sequence of this SNP is illustrated in Supplemental Figure S2 (UCSC Genome Browser, genome.ucsc.edu).

EDTA-anticoagulated whole blood was used for genotyping. DNA was extracted with the Autopure LS automated system according to the manufacturer's recommendations (Qiagen, Hilden, Germany).

For the analysis of the tetranucleotide repeat (rs3063368), as formerly described, a fragment length polymorphism PCR with fluorescently labeled primers and fragment length analysis via capillary electrophoresis was applied [10]. Of note, with this technique a phase analysis with the rs755622 single nucleotide polymorphism (SNP) is not possible. DNA was amplified in a Mastercycler gradient (Eppendorf AG, Germany). The PCR reaction mix contained $2.5 \mu \mathrm{L} 10 \times \mathrm{PCR}$ buffer, $3 \mu \mathrm{L}(25 \mathrm{mM}) \mathrm{MgCl} 2$, $2 \mu \mathrm{L}$ dNTP Mix, $0.8 \mu \mathrm{L}$ of each primer, $0.15 \mu \mathrm{L}(1 \mathrm{U})$ Taq polymerase, and $13.75 \mu \mathrm{L}$ of purified DNA, in a total end volume of $25 \mu \mathrm{L}$. The PCR consisted of the following steps: an initial denaturation step $\left(95^{\circ} \mathrm{C}, 12 \mathrm{~min}\right.$ ), 35 amplification cycle $\left(95^{\circ} \mathrm{C}, 30 \mathrm{~s} ; \mathrm{X}\right.$ (primer annealing temperature see Supplemental Table S1, $30 \mathrm{~s} ; 72{ }^{\circ} \mathrm{C}, 30 \mathrm{~s}$ ) and a final elongation step $\left(72{ }^{\circ} \mathrm{C}, 10 \mathrm{~min}\right)$. The reverse primer was labeled with 6-Carboxyfluorescein (6-FAM) [19]. The PCR was performed in a SimpliAmp Thermal Cycler (Life Technologies, Carlsbad, CA, USA). The PCR products were subjected to capillary electrophoresis on an ABI 3730XL Genetic Analyzer (Applied Biosystems, Foster City, CA, USA). Data collection was performed with Data Collection v3.0 software (Applied Biosystems, Foster City, CA, USA) and the results were analyzed by GeneMapper ID v5 software (Applied Biosystems, Foster City, CA, USA).

\subsection{Nomenclature and Genotyping of the SNP G>C Substitution (rs755622)}

The SNP rs755622 is a substitution of $\mathrm{G}>\mathrm{C}$ in the non-coding region at position chr22:23,894,205 (GRCh38.p12). Based on the older transcript annotations (NM_002415.1), this SNP has been formerly described with the position NM_002415.1:m.-173. According to the more accurate transcript annotation (NM_002415.2), the G>C substitution is located at position NM_002415.2:m.-178 and NM_002415.2:c.-270 G>C. (The start codon is located at position chr22:23,894,475.)

DNA was extracted from EDTA-anticoagulated whole blood with Autopure (Qiagen, Hilden, Germany). Genotyping of the SNP rs755622 G $>C$ was performed using an Assays-on-Demand ${ }^{\circledR}$ allelic discrimination on a TaqMan platform according to the manufacturer's instructions (ThermoFisher Scientific, Waltham, MA, USA). The polymerase chain reaction (PCR) contained $10 \mathrm{ng}$ of genomic DNA, $10 \mu \mathrm{L}$ TaqMan master mix, and $0.125 \mu \mathrm{L}$ of $40 \times$ assay mix. PCR was performed using 96 -well plates on an ABI 9700 thermal cycler (Applied Biosystems, Foster City, CA, USA) (reaction conditions $50{ }^{\circ} \mathrm{C}$ for $2 \mathrm{~min}, 95^{\circ} \mathrm{C}$ for $10 \mathrm{~min}$, followed by 40 cycles of $95^{\circ} \mathrm{C}$ for $15 \mathrm{~s}$ and $60^{\circ} \mathrm{C}$ for $1 \mathrm{~min}$ ). The TaqMan 7700 platform was used to perform an end-plate reading using the allelic discrimination option.

Sample and marker quality control (QC) was performed with PLINK (v1.9; https://www.coggenomics.org/plink/1.9)(PMID:25722852).

\subsection{Statistics}

Baseline characteristics were analyzed using of Wilcoxon Rank Sum test for continuous variables and Fisher's exact test for binary variables. Associations between MIF polymorphisms and outcome 
parameters were analyzed using univariate logistic regression and results are presented together with odds ratios and $95 \%$ confidence intervals.

Multivariable logistic regression analysis was performed to analyze the influence of relevant baseline variables. Model selection was based on the postoperative complication (dependent variable) and the genotype (independent variable). Further variables were selected on the basis of univariate analyses and significant differences. Model selection was accomplished by a backward elimination or a stepwise procedure.

Serum MIF levels at individual time points were compared using Wilcoxon Rank Sum test according to the MIF genotype. Analyses were calculated with SAS 9.4 (SAS Institute Inc., Cary, NC, USA) and SPSS (IBM SPSS, version 21.0, Armonk, NY, USA). All $p$-Values refer to two-sided tests, and $p<0.05$ was considered statistically significant.

\subsection{Study Approval}

Each patient provided written informed consent prior to inclusion in the study.

\section{Results}

\subsection{Patients, Baseline Characteristics, and Postoperative Complications}

The median age was 68 years and 25.1\% were females (Table 1). Postoperative AKI was associated with older age $(p<0.001)$, female gender $(p=0.007)$, the intake of aspirin $(p=0.01)$, lower baseline hemoglobin $(<14 \mathrm{~g} / \mathrm{dL})(p<0.001)$, peripheral artery disease $(p=0.02)$, hypertension $(p=0.01)$, insulin-dependent diabetes mellitus (IDDM) $(p=0.01)$, and a higher EuroSCORE $(p<0.001)$ (Table 1$)$. Death was associated with older age $(p=0.03)$ and IDDM $(p=0.03)$ (Table 1$)$.

Table 1. Baseline and operative characteristics by AKI and death.

\begin{tabular}{|c|c|c|c|c|c|c|c|c|c|c|}
\hline \multirow{2}{*}{ Demographics } & \multicolumn{4}{|c|}{ AKI } & \multirow[b]{2}{*}{$p$-Value } & \multicolumn{5}{|c|}{ Death } \\
\hline & \multicolumn{2}{|c|}{$\begin{array}{c}\text { Yes } \\
(N=170)\end{array}$} & \multicolumn{2}{|c|}{$\begin{array}{c}\text { No } \\
(N=946)\end{array}$} & & \multicolumn{2}{|c|}{$\begin{array}{c}\text { Yes } \\
(N=8)\end{array}$} & \multicolumn{2}{|c|}{$\begin{array}{c}\text { No } \\
(N=1108)\end{array}$} & $p$-Value \\
\hline Age, years & 72 & $(66-77)$ & 67 & $(58-73)$ & $<0.001$ & 73 & $(70-80)$ & 68 & $(59-73)$ & 0.03 \\
\hline Sex (female) & 57 & $(33.5)$ & 223 & (23.6) & 0.007 & 3 & $(37.5)$ & 277 & $(25.0)$ & 0.42 \\
\hline Active smokers & 32 & $(18.8)$ & 198 & (20.9) & 0.61 & 1 & (12.5) & 229 & (20.7) & 1.00 \\
\hline \multicolumn{11}{|l|}{ Medication } \\
\hline Beta blockers & 109 & (64.1) & 587 & (62.1) & 0.67 & 6 & (75.0) & 690 & (62.3) & 0.72 \\
\hline ACE inhibitors & 91 & (53.5) & 478 & (50.5) & 0.51 & 3 & (37.5) & 566 & (51.1) & 0.50 \\
\hline Cholesterol-lowering drug & 110 & (64.7) & 624 & (66.0) & 0.79 & 6 & (75.0) & 728 & (65.7) & 0.72 \\
\hline Insulin & 21 & (12.4) & 77 & $(8.1)$ & 0.08 & 3 & (37.5) & 95 & $(8.6)$ & 0.03 \\
\hline Aspirin & 128 & (75.3) & 619 & (65.4) & 0.01 & 4 & $(50.0)$ & 743 & $(6.0)$ & 0.45 \\
\hline Clopidogrel & 17 & (10) & 76 & $(8.0)$ & 0.37 & 2 & $(25.0)$ & 91 & $(8.2)$ & 0.14 \\
\hline \multicolumn{11}{|l|}{ Comorbidities } \\
\hline Hypertension & 153 & $(90.0)$ & 772 & (81.6) & 0.01 & 6 & $(75.0)$ & 919 & $(82.9)$ & 0.63 \\
\hline Ischemic heart disease & 132 & (77.6) & 706 & (74.6) & 0.39 & 5 & (62.5) & 833 & (75.2) & 0.42 \\
\hline Previous MI & & & & & & 1 & (12.5) & 315 & (28.4) & 0.45 \\
\hline Congestive heart disease & 43 & (25.3) & 193 & (20.4) & 0.15 & 2 & $(25.0)$ & 234 & (21.1) & 0.68 \\
\hline PAD & 20 & (11.8) & 62 & (6.6) & 0.02 & 2 & $(25.0)$ & 80 & $(7.2)$ & 0.68 \\
\hline COPD & 15 & $(8.8)$ & 80 & (8.5) & 0.88 & 0 & 0 & 95 & (8.6) & 1.00 \\
\hline Chronic kidney disease & 24 & (14.1) & 107 & (11.3) & 0.30 & 1 & (12.5) & 130 & (11.7) & 1.00 \\
\hline IDDM & 56 & (32.9) & 219 & (23.2) & 0.01 & 4 & $(50.0)$ & 271 & (24.5) & 0.11 \\
\hline \multicolumn{11}{|l|}{ Laboratory, at baseline } \\
\hline Serum creatinine $\mathrm{mg} / \mathrm{dL}$ & 0.92 & $(0.8-1.1)$ & 0.91 & $(0.8-1.1)$ & 0.66 & 0.99 & $(0.73-1.14)$ & 0.91 & $(0.80-1.07)$ & 0.82 \\
\hline Hemoglobin, g/dL & 13.6 & $(12.5-14.6)$ & 14.2 & $(13.4-14.9)$ & $<0.001$ & 13.6 & $(12.1-14.4)$ & 14.1 & $(13.2-14.9)$ & 0.31 \\
\hline \multicolumn{11}{|l|}{ EuroSCORE } \\
\hline & 5 & $(3-7)$ & 4 & $(2-6)$ & $<0.001$ & 6 & $(5-8)$ & 4 & $(2-6)$ & 0.03 \\
\hline \multicolumn{11}{|l|}{ Type of surgery } \\
\hline CABG (alone) & 64 & (37.6) & 434 & $(45.9)$ & & 3 & (37.5) & 495 & $(44.7)$ & \\
\hline Aortic valve * & 37 & (12.8) & 190 & (20.1) & & 2 & (12.5) & 225 & (20.3) & \\
\hline Mitral valve* & 6 & (3.5) & 32 & (3.4) & & 0 & (37.5) & 38 & (3.4) & \\
\hline Aorta ascendens * & 3 & (1.8) & 30 & (3.2) & 0.26 & 0 & (25.0) & 33 & (3.0) & 0.25 \\
\hline Combined procedures & 57 & (33.5) & 245 & $(25.9)$ & & 2 & 25.0 & 300 & (27.1) & \\
\hline Other type of surgery & 3 & (1.8) & 15 & (1.6) & & 1 & 12.5 & 17 & (1.5) & \\
\hline
\end{tabular}

Data are expressed as the median and interquartile range (Q1-Q3) or absolute numbers and (percentage). The association of baseline characteristics with AKI and death was analyzed by Wilcoxon rank sum or Fisher's exact test. $\mathrm{ACE}$, angiotensin converting enzyme; $\mathrm{CABG}$, coronary artery bypass graft; $\mathrm{COPD}$, chronic obstructive pulmonary disease; IDDM, insulin-dependent diabetes mellitus; MI, myocardial infarction; PAD, peripheral artery disease, ${ }^{*}$, replacement or reconstruction (alone). Bold fonts indicate $p$-values $<0.05$. 


\subsection{Genotype Frequencies}

The most common genotypes were CATT $_{6,6}$-GG (32.3\%) and CATT 5,6 -GG (30.9\%) (Table 2); $24.8 \%$ of patients carried at least one $\mathrm{CATT}_{7}$ allele; $29.6 \%$ of patients were heterozygous and $2.3 \%$ of patients were homozygous carriers of the $\mathrm{G}>\mathrm{C}$ substitution. The allele frequencies in our study cohort were comparable to the frequencies published in the reference database gnomAD (Table 1) [20]. The frequency of the GC genotype and the $\mathrm{CATT}_{7}$-repeat allele was higher than in patients with AKI compared to patients without AKI ( $X^{2}$ test for trend, $p=0.001$ ) (Figure 1$)$.

Table 2. Frequencies of the MIF $\mathrm{CATT}_{5-7}$ repeat allele (rs3063368) and the G>C single-nucleotide polymorphism (rs755622) in 1116 patients undergoing cardiac surgery.

\begin{tabular}{|c|c|c|c|}
\hline \multicolumn{4}{|c|}{ CATT $_{5-7}$ Repeat Allele Carrier Frequencies (rs3063368) } \\
\hline & N Carriers & $\%$ & Allele Frequency (Europe) $\%{ }^{1}$ \\
\hline $\mathrm{CATT}_{5}$ & 488 & 43.7 & $-*$ \\
\hline $\mathrm{CATT}_{6}$ & 957 & 85.8 & 84.3 \\
\hline $\mathrm{CATT}_{7}$ & 277 & 24.8 & 24.9 \\
\hline \multicolumn{4}{|c|}{ G>C SNP Genotype Frequencies (rs755622) } \\
\hline & N Genotypes & $\%$ & Allele Frequency (Europe) $\%^{1}$ \\
\hline GG (homozygous) & 762 & 68.3 & 65.2 \\
\hline GC (heterozygous) & 328 & 29.4 & 31.7 \\
\hline CC (homozygous) & 26 & 2.3 & 3.1 \\
\hline \multicolumn{4}{|c|}{ Individual Genotype Combination Frequencies (rs3063368 \& rs755622) } \\
\hline & $N$ & $\%$ & \\
\hline $\mathrm{CATT}_{5,5}-\mathrm{GG}$ & 68 & 6.1 & \\
\hline CATT $_{5,6}$-GG & 329 & 29.5 & \\
\hline CATT $_{6,6}-\mathrm{GG}$ & 360 & 32.3 & \\
\hline CATT $_{5,7}$-GG & 2 & 0.2 & \\
\hline CATT $_{6,7}$-GG & 3 & 0.3 & \\
\hline CATT $_{5,5}-\mathrm{CG}$ & 3 & 0.3 & \\
\hline CATT $_{5,6}-\mathrm{CG}$ & 16 & 1.4 & \\
\hline CATT $_{6,6}-\mathrm{CG}$ & 63 & 5.6 & \\
\hline CATT $_{5,7}-\mathrm{CG}$ & 69 & 6.2 & \\
\hline $\mathrm{CATT}_{6,7}-\mathrm{CG}$ & 176 & 15.8 & \\
\hline CATT $_{7,7}-\mathrm{CG}$ & 1 & 0.1 & \\
\hline CATT $_{5,7}-\mathrm{CC}$ & 1 & 0.1 & \\
\hline CATT $_{6,7}-\mathrm{CC}$ & 10 & 0.9 & \\
\hline CATT $_{7,7}-\mathrm{CC}$ & 15 & 1.3 & \\
\hline All & 1116 & 100.00 & \\
\hline
\end{tabular}

The most frequent genotypes observed were CATT ${ }_{5,6}$-GG (29.5\%), CATT ${ }_{6,6}-\mathrm{GG}(32.3 \%)$, and CATT ${ }_{6,7}$-CG (15.8\%). The frequency of the polymorphisms was comparable to the frequency in the general reference population (Europe) ${ }^{1}$; SNP, Single nucleotide polymorphism; $\mathrm{CATT}_{7}$, patients carrying at least one $\mathrm{CATT}_{7}$ allele. Data presented as absolute numbers and percentage. ${ }^{1}$ calculated from reference gnomAD Database (including $>7500$ genomes from unrelated non-Finnish European individuals sequenced as part of various population genetic studies) [20]. ${ }^{*}$ As $_{\text {CATT }}$ is the wildtype allele, there is no information regarding CATT ${ }_{5}$ in the gnomAD Database. 

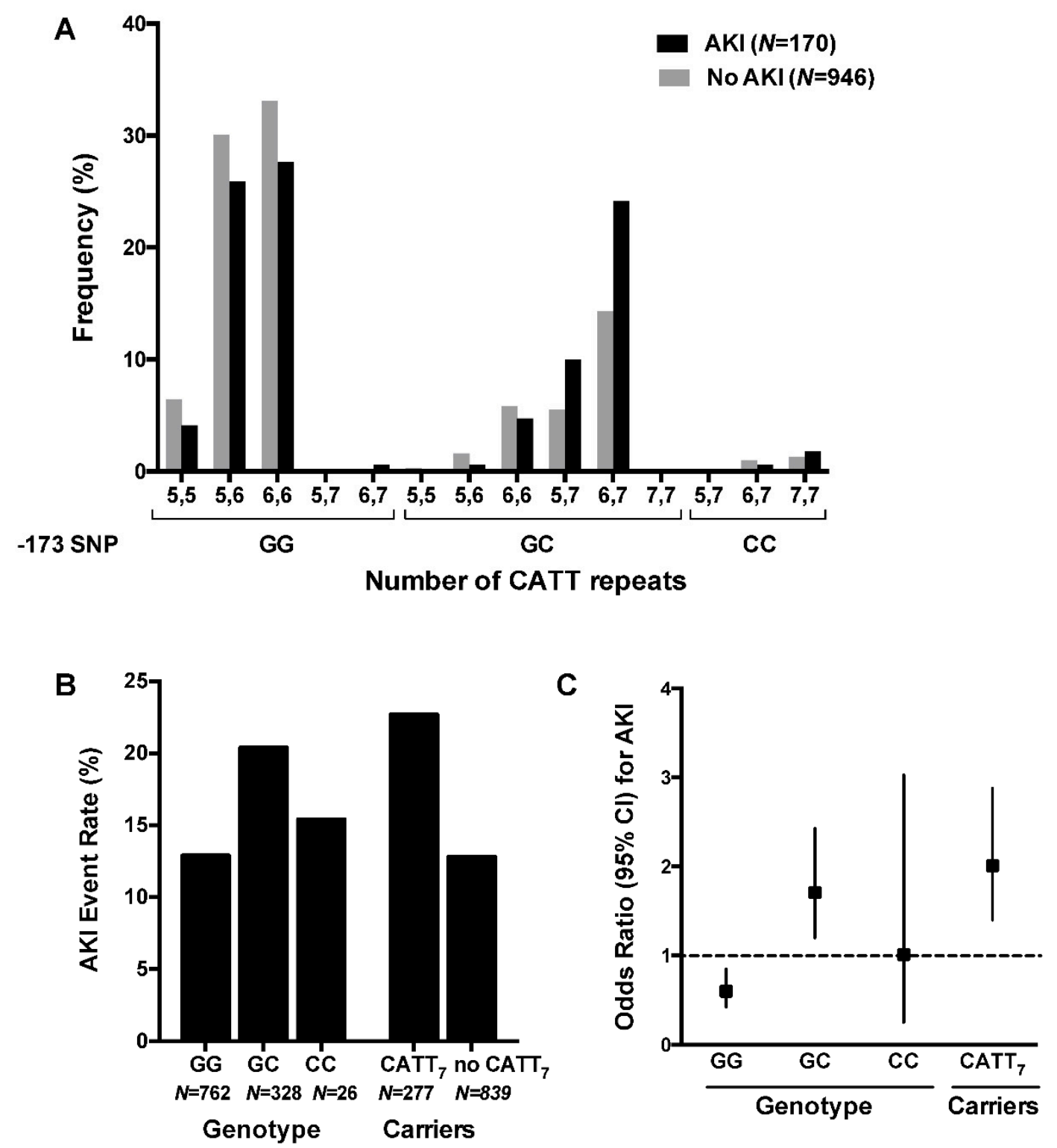

Figure 1. Frequency distribution of the CATT microsatellite repeat (rs3063368) and the G>C SNP (rs755622) in patients with AKI versus patients not affected by AKI after cardiac surgery. (A) In patients with AKI, the frequency of the GC genotype and the $\mathrm{CATT}_{7}$ allele is higher than in patients without AKI $\left(X^{2}\right.$ test for trend, $\left.p=0.001\right)$. (B) The AKI event rate was higher in patients with the GC genotype (20\%) versus patients with the CC or the GG genotype (13\%), and higher in $\mathrm{CATT}_{7}$ carriers $(23 \%)$ compared to non-carriers. (C) Patients carrying the GC genotype or the $\mathrm{CATT}_{7}$ allele had a significantly increased relative risk of AKI compared to all other patients.

3.3. Association of the Tetranucleotide Repeat $\mathrm{CATT}_{5-7}$ (rs3063368) and the G>C Single-Nucleotide Polymorphism (rs755622) with Postoperative Outcome

All patients $(N=1116)$ were examined for the association between the two polymorphisms in the MIF promoter and risk of postoperative complications. The overall incidence of AKI after cardiac surgery was $15.2 \%(N=170)$ (Table 3$)$. Patients who were either homozygous or heterozygous carriers of the MIF CATT 7 allele had a significantly increased risk of AKI after cardiac surgery when compared to all other patients (22.7\% vs. $12.8 \%$, OR $2.01,95 \%$ CI $1.40-2.88, p=0.0001)$ (Table 4$)$. 
Table 3. Absolute and relative frequency of postoperative complications. * Patients affected by at least two of the predefined organ dysfunctions.

\begin{tabular}{ccc}
\hline & \multicolumn{2}{c}{ Patients $(\mathbf{N}=\mathbf{1 1 1 6})$} \\
& $\mathbf{N}$ & $\mathbf{\%}$ \\
\hline Death & 8 & 0.7 \\
Myocardial infarction (MI) & 93 & 8.3 \\
Stroke & 24 & 2.2 \\
Delirium & 144 & 12.9 \\
Acute kidney injury (AKI) & 170 & 15.2 \\
Stage 1 & 108 & 9.7 \\
Stage 2 & 38 & 3.4 \\
Stage 3 & 24 & 2.1 \\
Atrial Fibrillation & 245 & 21.9 \\
\hline Multiple Complications $(\geq) *$ & 139 & 12.4 \\
\hline
\end{tabular}

Table 4. Association of the MIF promoter polymorphisms with AKI.

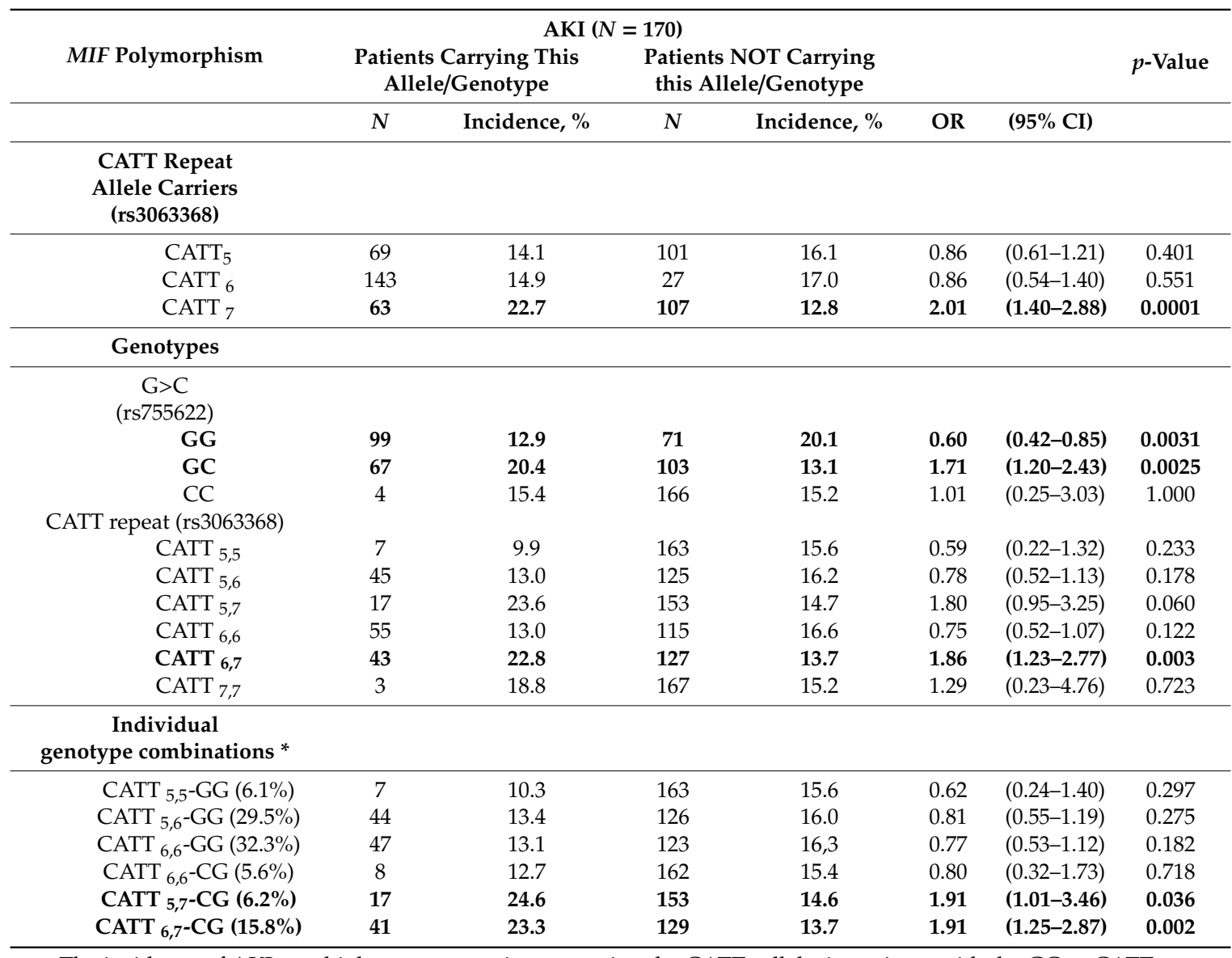

The incidence of AKI was higher among patients carrying the $\mathrm{CATT}_{7}$ allele, in patients with the GC or CATT 6,7 genotype, and in patients with the genotype combinations CATT $5,7-\mathrm{CG}$ and CATT $6,7-\mathrm{CG}$. AKI, acute kidney injury; $\mathrm{CI}$, confidence interval; OR, odds ratio; SNP, Single nucleotide polymorphism; $\mathrm{CATT}_{7}$, patients carrying at least one $\mathrm{CATT}_{7}$ allele. ${ }^{*}$ genotype combinations with a frequency of $>5 \%$. Data presented as absolute numbers and percentage. $p$-value calculated by Fisher exact test; bold fonts indicate $p$-values $<0.05$.

Patients carrying the G>C SNP were also at increased risk of AKI $(20.4 \%$ vs. $13.1 \%$, OR $1.71,95 \%$ CI 1.20-2.43, $p=0.0025$ ) (Table 4). The 26 homozygote carriers of the CC genotype did not show an increased risk of AKI when compared to others $(p=1.000)$.

Multiple complications, defined as at least two of the predefined organ dysfunctions, were observed in $12.4 \%$ of patients $(N=139)$ (Table 3$)$. The $\mathrm{CATT}_{7}$ repeat and the G>C SNP were significantly associated with the occurrence of multiple postoperative complications when compared 
to all other genotypes $\left(\mathrm{CATT}_{7}: 17.7 \%\right.$ vs. $10.7 \%$, OR 1.79, 95\% CI 1.20-2.65, $p=0.003$; GC: $16.8 \%$ vs. $10.7 \%$, OR $1.69,95 \%$ CI 1.15-2.47, $p=0.007$ ) (Table 5).

Table 5. Association of the MIF promoter polymorphisms with multiple complications *.

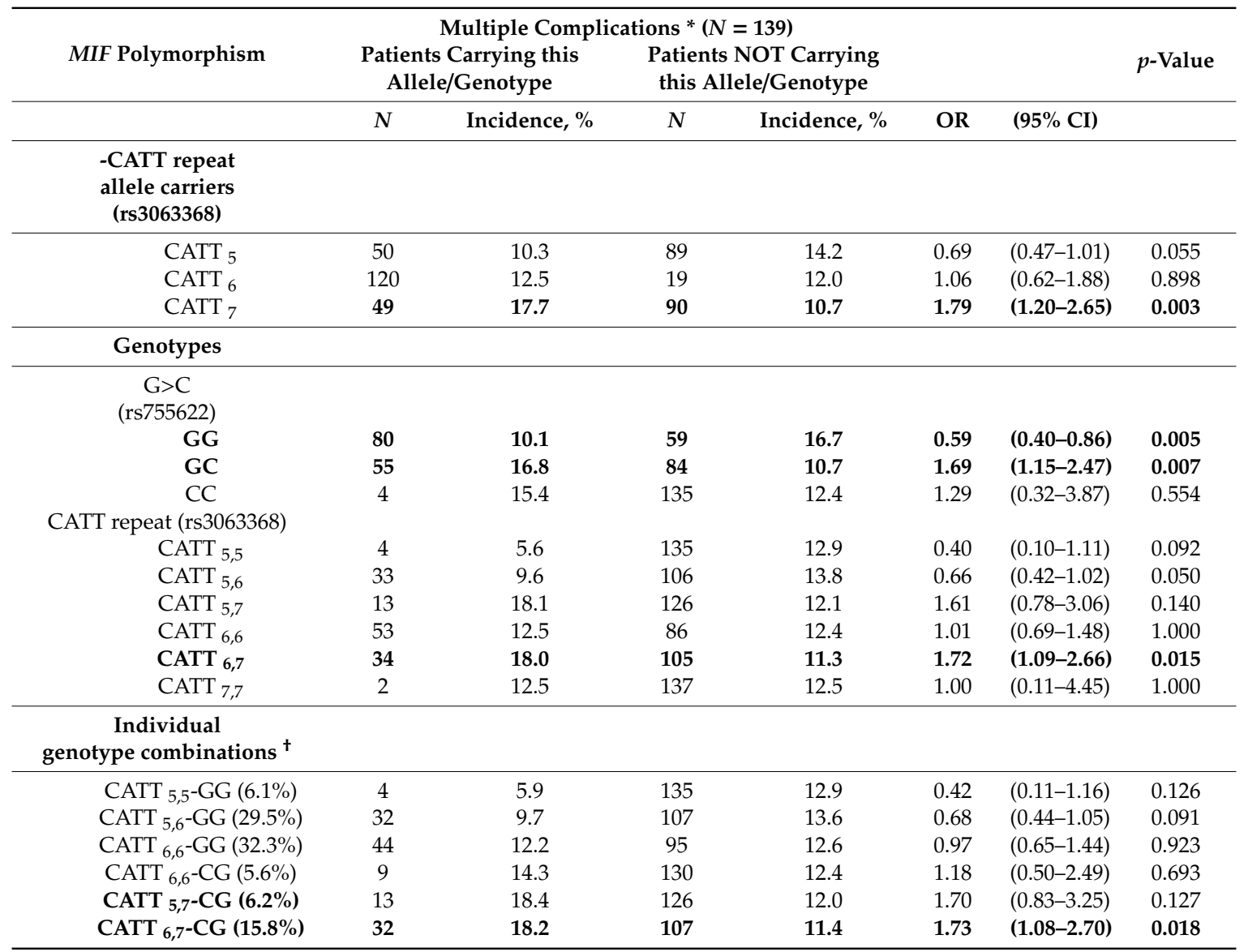

The incidence of multiple complications was higher among patients carrying the $\mathrm{CATT}_{7}$ allele, in patients with the GC or CATT 6,7 genotype, and in patients with the genotype combinations CATT ${ }_{5,7}$-CG and CATT $6,7-\mathrm{CG}$. $\mathrm{CI}$, confidence interval; OR, odds ratio; $\mathrm{SNP}$, Single nucleotide polymorphism; $\mathrm{CATT}_{7 \mathrm{x}}$, patients carrying at least one $\mathrm{CATT}_{7}$ allele. ${ }^{\dagger}$ genotype combinations with a frequency of $>5 \% .{ }^{*}$ Patients affected by at least two of the predefined organ dysfunctions. ${ }^{\dagger}$ defined as at least two of the predefined organ dysfunctions. Data presented as absolute numbers and percentage. $p$-value calculated by Fisher's exact test; bold fonts indicate $p$-values $<0.05$.

The incidence of death during the first 30 days after surgery was $0.7 \%(N=8)$ (Table 3$)$. The mortality of carriers of the MIF CATT 7 allele was significantly higher compared to patients not carrying the $\mathrm{CATT}_{7}$ repeat ( $1.81 \%$ vs. $0.36 \%, p=0.026$, OR $5.12,95 \%$ CI $0.99-33.14$ ) (Table 6 ). Likewise, patients with the MIF CATT C,7 $_{7}$ repeat genotype also had an increased risk of death when compared to all other patients $(2.1 \%$ vs. $0.4 \%$, OR $4.99,95 \%$ CI $0.92-26.98, p=0.032)$. Mortality rates in carriers of the GC genotype were increased with borderline significance (1.5\% vs. $0.4 \%$, OR $4.05,95 \%$ CI $0.78-26.20$, $p=0.053)$.

There was no significant difference in the incidence of AKI or death in heterozygous or homozygous carriers of the C allele or the CATT7 repeat allele (AKI-C-allele: $20.4 \%$ vs. $15.4 \%$, OR $1.41(0.47-4.24)$, $p=0.537$; AKI-CATT7: $21.7 \%$ vs. $18.8 \%$, OR 1.11 (0.30-4.05), $p=0.879$; death-C allele: $0 \%$ vs. $1.5 \%$, OR 0.90 (0.05-16.75), $p=0.526$; death-CATT7: $0 \%$ vs. 1.9\%; OR $0.66(0.03-12.54), p=0.589)$. While MIF promoter polymorphisms were significantly associated with AKI, multiple complications, and death, no significant association was found with regards to the incidence of postoperative myocardial infarction, atrial fibrillation, stroke, or delirium (Supplemental Tables S2-S5). 
Table 6. Association of the MIF promoter polymorphisms with death.

\begin{tabular}{|c|c|c|c|c|c|c|c|}
\hline \multirow{3}{*}{ MIF Polymorphism } & \multicolumn{4}{|c|}{ Death $(N=8)$} & \multirow[b]{3}{*}{ OR } & \multirow[b]{3}{*}{$(95 \%$ CI $)$} & \multirow{3}{*}{$p$-Value } \\
\hline & \multicolumn{2}{|c|}{$\begin{array}{l}\text { Patients Carrying This } \\
\text { Allele/Genotype }\end{array}$} & \multicolumn{2}{|c|}{$\begin{array}{l}\text { Patients NOT Carrying } \\
\text { This Allele/Genotype }\end{array}$} & & & \\
\hline & $N$ & Incidence, \% & $N$ & Incidence, $\%$ & & & \\
\hline \multicolumn{8}{|l|}{$\begin{array}{l}\text { CATT repeat } \\
\text { allele carriers } \\
\text { (rs3063368) }\end{array}$} \\
\hline $\mathrm{CATT}_{5}$ & 2 & 0.4 & 6 & 1.0 & 0.43 & $(0.04-2.40)$ & 0.478 \\
\hline $\mathrm{CATT}_{6}$ & 7 & 0.7 & 1 & 0.6 & 1.16 & $(0.15-52.80)$ & 1.000 \\
\hline CATT $_{7}$ & 5 & 1.8 & 3 & 0.4 & 5.12 & $(0.99-33.14)$ & 0.026 \\
\hline \multicolumn{8}{|l|}{ Genotypes } \\
\hline \multicolumn{8}{|l|}{$\begin{array}{c}\mathrm{G}>\mathrm{C} \\
(\mathrm{rs} 755622)\end{array}$} \\
\hline GG & 3 & 0.4 & 5 & 1.4 & 0.28 & $(0.04-1.43)$ & 0.118 \\
\hline GC & 5 & 1.5 & 3 & 0.4 & 4.05 & $(0.78-26.20)$ & 0.053 \\
\hline $\mathrm{CC}$ & 0 & 0 & 8 & 0.7 & 0.00 & $(0.00-19.77)$ & 1.000 \\
\hline \multicolumn{8}{|l|}{ CATT repeat (rs3063368) } \\
\hline CATT $_{5,5}$ & 0 & 0 & 8 & 0.8 & 0.00 & $(0.00-6.75)$ & 1.000 \\
\hline CATT $_{5,6}$ & 1 & 0.3 & 7 & 0.9 & 0.32 & $(0.01-2.49)$ & 0.447 \\
\hline CATT $_{5,7}$ & 1 & 1.4 & 7 & 0.7 & 2.09 & $(0.05-16.59)$ & 0.415 \\
\hline CATT $_{6,6}$ & 2 & 0.5 & 6 & 0.9 & 0.54 & $(0.05-3.06)$ & 0.717 \\
\hline CATT $_{6,7}$ & 4 & 2.1 & 4 & 0.4 & 4.99 & $(0.92-26.98)$ & 0.032 \\
\hline CATT $_{7,7}$ & 0 & 0 & 8 & 0.7 & 0.00 & $(0.00-33.33)$ & 1.000 \\
\hline \multicolumn{8}{|l|}{$\begin{array}{c}\text { Individual } \\
\text { genotype combinations * }\end{array}$} \\
\hline 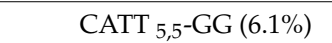 & 0 & 0 & 8 & 0.8 & 0.00 & $(0.00-7.07)$ & 1.000 \\
\hline CATT $_{5,6}$-GG $(29.5 \%)$ & 1 & 0.3 & 7 & 0.9 & 0.34 & $(0.01-2.66)$ & 0.449 \\
\hline CATT $_{6,6}$-GG $(32.3 \%)$ & 2 & 0.6 & 6 & 0.8 & 0.70 & $(0.07-3.93)$ & 1.000 \\
\hline CATT $_{6,6}{ }^{0}$ CG $(5.6 \%)$ & 0 & 0 & 8 & 0.8 & 0.00 & $(0.00-7.68)$ & 1.000 \\
\hline CATT $_{57}-\mathrm{CG}(6.2 \%)$ & 1 & 1.5 & 7 & 0.7 & 2.18 & $(0.05-17.39)$ & 0.401 \\
\hline CATT $_{6,7}$-CG (15.8\%) & 4 & 2.3 & 4 & 0.4 & 5.44 & $(1.00-29.44)$ & 0.025 \\
\hline
\end{tabular}

The incidence of death was higher among patients carrying the $\mathrm{CATT}_{7}$ allele, in patients with the CATT 6,7 genotype, and in patients with the genotype combination CATT $6,7-$ CG.; OR, odds ratio; SNP, Single nucleotide polymorphism; $\mathrm{CATT}_{7}$, patients carrying at least one $\mathrm{CATT}_{7}$ allele. ${ }^{*}$ genotypes with a frequency of $>5 \%$. Data presented as absolute numbers and percentage. $p$-value calculated by Fisher's exact test; bold fonts indicate $p$-values $<0.05$.

\subsection{MIF Genotypes as a Predictor of AKI in Multivariable Analyses}

To assess if the MIF genotype improves preoperative risk prediction, a multivariable logistic regression was performed for AKI and death. For risk modeling, all baseline patients' characteristics (Table 1), including the well-established EuroSCORE, a preoperative risk stratification tool, were considered, and a logistic regression parameter selection procedure was performed. For the prediction of AKI, the variables EuroSCORE, hemoglobin, hypertension, and the presence of the MIF $\mathrm{CATT}_{7}$ allele were selected. When adjusted for these variables, the MIF CATT 7 allele remained a significant predictor of AKI (OR 2.13, 95\% CI, 1.46-3.1) (Table 7). The resulting model had an AUC of $0.71(95 \%$ CI, 0.67-0.76).

For prediction of death, the statistical variable selection procedure resulted in a model containing the variables EuroSCORE, insulin-dependent diabetes, and the MIF $\mathrm{CATT}_{7}$ allele. The presence of a MIF CATT $_{7}$ repeat allele significantly improved the prediction of postoperative mortality in this model (OR 5.58, 95\% CI 1.29-24.04, $p=0.021$ ). The resulting model had an AUC (receiver operating statistics-area under the curve) of 0.874 (95\% CI, 0.786-0.962) (Table 7, Figure 2). In summary, the MIF $\mathrm{CATT}_{7}$ allele is a significant predisposing risk factor for AKI and death after cardiac surgery.

The multivariable logistic regression model for AKI includes the variables MIF CATT 7 allele carriers and arterial hypertension as binary variables, and EuroSCORE and hemoglobin levels as continuous variables (according to Table 7). The model for death includes the variables MIF CATT 7 carrier status and insulin-dependent diabetes as binary variables and EuroSCORE as a continuous variable. AUC, area under the curve; $\mathrm{CI}$, confidence interval. 
Table 7. Predictors of Acute Kidney Injury (AKI) and death using multivariable logistic regression.

\begin{tabular}{|c|c|c|c|c|}
\hline Variable & B & OR & $\begin{array}{c}(95 \% \\
\text { CI })\end{array}$ & $p$-Value \\
\hline AKI $(N=170) *$ & -1.066 & & & \\
\hline $\mathrm{CATT}_{7}$ carrier & 0.755 & 2.13 & $(1.46-3.09)$ & $<0.001$ \\
\hline EuroSCORE & 0.202 & 1.22 & $(1.38-1.32)$ & $<0.001$ \\
\hline Hemoglobin & -0.183 & 0.83 & $(0.74-0.94)$ & 0.004 \\
\hline Hypertension & 0.701 & 2.03 & $(1.11-3.72)$ & 0.022 \\
\hline Death $(N=8)^{\dagger}$ & -6.709 & & & \\
\hline $\mathrm{CATT}_{7}$ carrier & 1.719 & 5.58 & $(1.29-24.04)$ & 0.021 \\
\hline EuroSCORE & 0.342 & 1.41 & $(1.05-1.88)$ & 0.021 \\
\hline IDDM & 1.923 & 6.84 & $(1.55-30.26)$ & 0.011 \\
\hline
\end{tabular}

In addition to the well-established EuroSCORE and other baseline characteristics, the MIF CATT 7 was identified as a significant predictor of AKI and death. AKI, acute kidney injury; OR, odds ratio; CI, confidence interval. IDDM, insulin-dependent diabetes mellitus. Bold fonts indicate $p$-values $<0.05$. * Area under the curve (AUC), $0.71 ; 95 \%$ CI, 0.67 - 0.76; Hosmer und Lemeshow Goodness-of-Fit Test, $0.8432 .{ }^{\dagger}$ Area under the curve (AUC), $0.87 ; 95 \%$ CI, 0.79-0.96; Hosmer und Lemeshow Goodness-of-Fit Test, 0.9702.

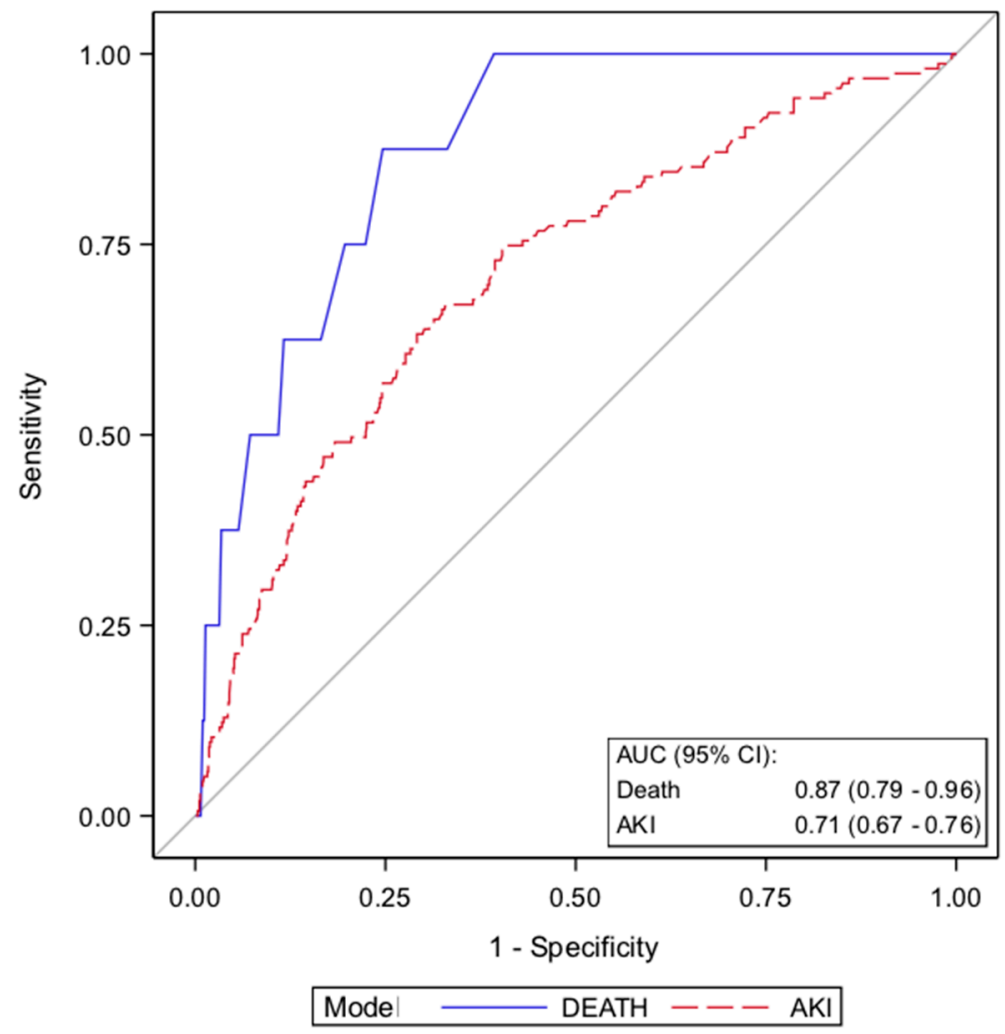

Figure 2. Receiver operating characteristics (ROC) curves for the prediction of AKI (red) and death (blue) after elective cardiac surgery. The grey line indicates the reference values of a diagnostic test that is no better than chance level.

\subsection{MIF Serum Levels Before Surgery Are Increased in Patients Carrying the $\mathrm{CATT}_{7}$ Allele}

To assess the association of the MIF promoter polymorphisms and the circulating MIF levels in cardiac surgery patients, perioperative kinetics of serum MIF were analyzed in 100 patients in relation to the underlying MIF polymorphisms. In patients carrying at least one $\mathrm{CATT}_{7}$ allele $\left(\mathrm{CATT}_{7}\right)$, serum MIF was significantly elevated before surgery $(79.2 \mathrm{vs} .50 .4 \mathrm{ng} / \mathrm{mL}, p=0.008)$ and one hour after surgery (154.8 vs. $79.5 \mathrm{ng} / \mathrm{mL}, p=0.02$ ) (Figure 3). The comparison of all other alleles, genotypes, and individual genotype combinations did not show significant differences between groups. 


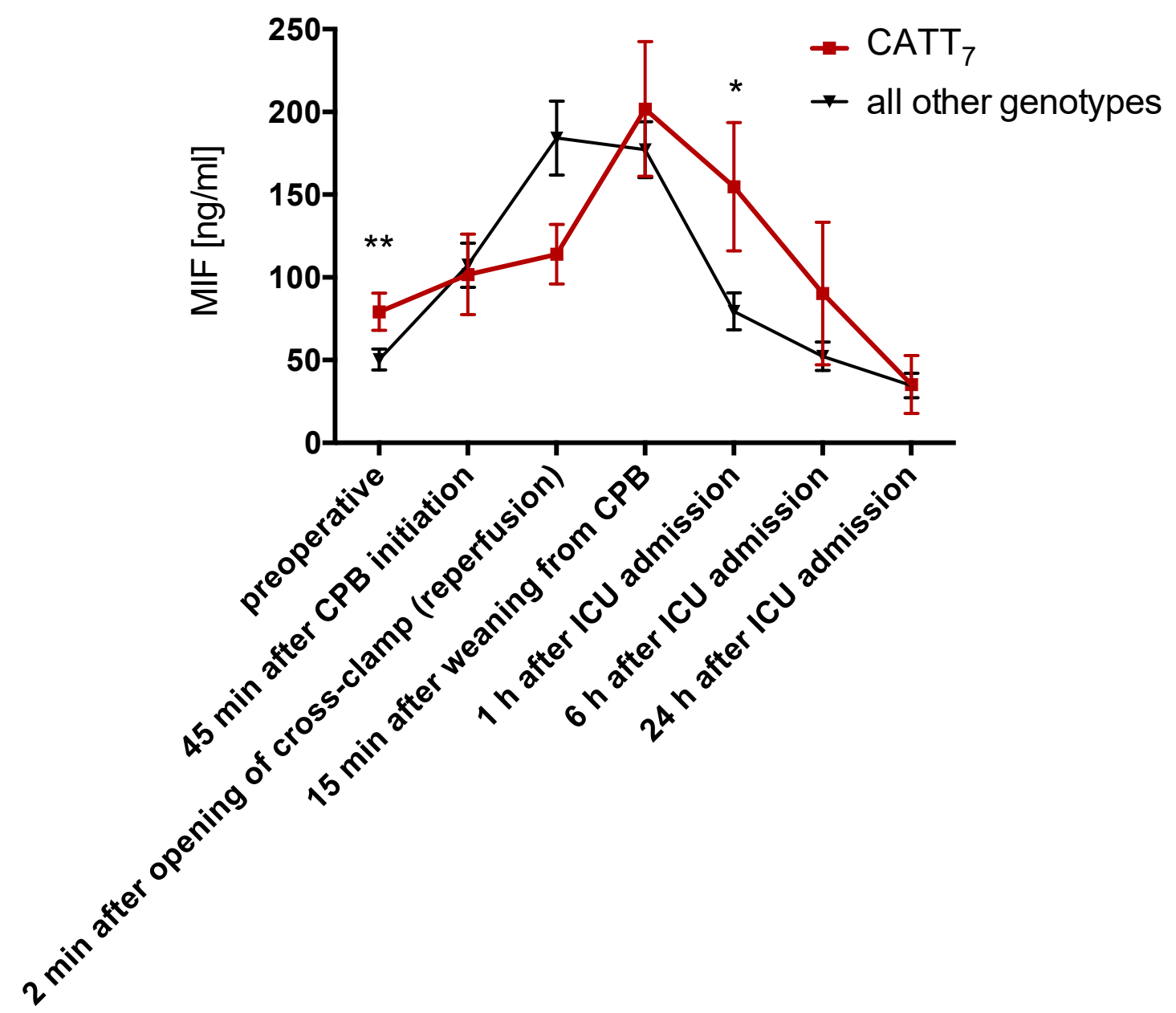

Figure 3. Perioperative kinetics of serum MIF in patients undergoing cardiac surgery. ${ }^{*} P<0.05,{ }^{* *} P<0.01$.

Serum MIF was quantified with ELISA in 100 patients. Patients heterozygous or homozygous for the MIF $\mathrm{CATT}_{7}$ allele had significantly increased serum MIF before surgery (preoperative) and significantly lower serum MIF $1 \mathrm{~h}$ after surgery. Data are means \pm SEM. ${ }^{* *} p<0.01,{ }^{*} p<0.05$ versus other groups at the corresponding time point (difference between groups) analyzed by Wilcoxon Rank Sum test.

\section{Discussion}

MIF is an inflammatory cytokine that is rapidly released from preformed intracellular pools in response to diverse cellular and systemic stressors, including ischemia-reperfusion, endotoxemia and surgery [21]. Previous studies demonstrated a significant peak of circulating MIF during cardiac surgery, as well as an association between circulating MIF and adverse postoperative outcomes [5,22-24].

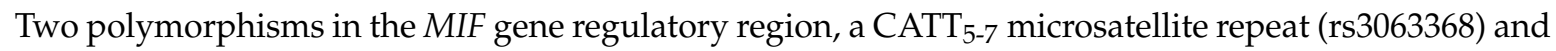
a -270 (formerly described as -173) G>C single-nucleotide polymorphism (rs755622), which is in linkage disequilibrium with $\mathrm{CATT}_{7}$, have been studied regarding their association with different pathologic conditions (e.g., pulmonary tuberculosis, acute coronary syndrome, carotid artery atherosclerosis, systemic lupus erythematosis, multiple sclerosis) [8,14,25-28]. However, the impact of the MIF gene polymorphisms on postoperative outcomes after cardiac surgery has not been analyzed.

The cardiac surgery patients in the present study displayed similar allele frequencies of the MIF $\mathrm{CATT}_{5-7}$ microsatellite repeat ( $\mathrm{rs3063368)}$ and $\mathrm{G}>\mathrm{C}$ single nucleotide variant (rs755622) as in the general population [20]. Approximately $25 \%$ of patients carried at least one longer CATT repeat $\left(\mathrm{CATT}_{7}\right)$ (rs3063368) and 30\% carried at least one C allele (rs755622). Demographic characteristics and procedural 
data revealed no significant differences between genotypes. Heterozygous or homozygous carriers of the $\mathrm{CATT}_{7}$ allele had an almost 5-fold increased risk of death after cardiac surgery. Patients carrying either the $\mathrm{CATT}_{7}$ or the $\mathrm{C}$ allele had an approximately 2-fold increased risk of suffering from AKI or multiple organ dysfunctions. While the risk for AKI was $12.8 \%$ in patients not carrying a $\mathrm{CATT}_{7}$ allele, it was $22.7 \%$ for carriers of the $\mathrm{CATT}_{7}$ allele. In addition to the well-established EuroSCORE, the MIF $\mathrm{CATT}_{7}$ was identified as a significant predictor of death and development of AKI in a multivariable logistic regression model. The reason why we observed no significant association between homozygosity of the CC genotype might be attributed to the very low number of patients ( $N=26$, frequency $2.3 \%$, but should be reevaluated in larger cohorts.

The MIF promoter microsatellite was suggested to influence MIF mRNA expression, as assessed by luciferase reporter assays in normal and patient cells $[11,14]$. The longer CATT $_{7}$ repeat further has been associated with higher serum MIF levels in various patient cohorts, including those with coronary artery disease $[10,29,30]$. In this study, we found that patients carrying the $\mathrm{CATT}_{7}$ allele had higher serum MIF preoperatively and one hour after surgery, but serum MIF did not differ at the other intraand postoperative timepoints.

In recent literature, MIF has already been associated with AKI in divergent clinical settings of septic shock, liver transplantation, glomerulonephritis, and renal allograft rejection [31-34].

However, there are indications that MIF can have a protective role against renal tubular injury in experimental models of ischemic AKI $[23,35]$. In one study, high MIF serum levels during cardiac surgery were associated with a reduced risk of postoperative AKI [23]. This contrasts with our observation of the $\mathrm{CATT}_{7}$ and $\mathrm{G}>\mathrm{C}$, that are the proposed high expression alleles, being associated with AKI. An important risk factor for postoperative AKI is pre-existing chronic kidney disease (CKD), genetic studies support an association between the presence of at least one MIF G>C allele (rs755622) with chronic kidney and cardiovascular disease [36,37]. In a cross-sectional study MIF serum levels were significantly increased in patients with CKD [38]. It is well established that chronic kidney disease (CKD) predisposes to AKI [39]. Therefore, it can be speculated that the association between proposed high expression MIF genotypes with AKI is related to CKD that may inflate the risk for postoperative AKI. We suggest that preoperatively, chronically elevated MIF serum levels are associated with detrimental effects and may need to be discriminated from high intraoperative MIF serum levels, which might in fact mediate organ-protective effects during ischemia-reperfusion. This is in line with the notion that acute elevations of MIF serum levels may ameliorate ischemia-reperfusion injury after cardiac surgery, whereas long-term elevations in MIF may aggravate inflammatory pathways in atherosclerosis $[40,41]$. The observation of MIF correlating with markers of oxidative stress (8-hydroxy-2-deoxyguanosine) and endothelial activation (ICAM-1) in a cohort of CKD patients, supports the thesis that chronically elevated MIF levels might contribute to cardiovascular and associated CKD [38].

Mechanistically, MIF induces intracellular signal cascades via binding to its receptors including the cardioprotective CD74/AMPK kinase axis and the MIF CXC motif chemokine receptors, CXCR2, CXCR4, or CXCR7. Serum MIF may influence the expression of MIF receptors, and there are indications from mouse models that genetic MIF deficiency downregulates the expression of the MIF-signalling co-receptor CD44, which is required for signaling responses through CD74 [42,43]. Accordingly, chronically elevated levels of MIF might lead to an altered or injurious response to an acute, perioperative MIF increase, and potentially explain why MIF may be renoprotective in healthy mice but deleterious in multimorbid patients with chronic, underlying inflammation. The results of the present study nevertheless remain observational and cannot explain causative pathophysiology. Further studies investigating the mechanisms by which high expression of the MIF genotype may mediate the observed deleterious effects may help in the development of protective strategies for high risk cardiac surgery patients.

We acknowledge several limitations of our study, including the observational design. The event rate for death was very low, and therefore the analysis addressing the association of MIF genotypes with mortality should be interpreted cautiously and requires validation in larger cohorts. Although we 
measured serum MIF in a subcohort of patients and observed a relationship with increased CATT repeat length, this observation has not been consistently observed in prior studies, in part due to limitations of the serum compartment in reflecting systemic or regional tissue MIF expression levels [44,45]. Moreover, the study focused on Caucasian subjects and population stratification at the MIF locus exists [46]. While we did not study different geographic cohorts, our homogenous study population allows generalisability across predominantly European populations. Finally, the genotyping technique employed does not allow a concise phase analysis, and single haplotypes, e.g., the co-localization of a specific CATT allele (rs3063368) with the G or C allele (rs755622), cannot be explored.

In the same study cohort, one genome-wide association study (GWAS) has been undertaken and did not identify an association of the MIF gene polymorphisms with postoperative outcome [47]. Therefore, our findings underscore the necessity of candidate gene studies, including of common structural variants such as microsatellite repeats that are not detectable by SNP-based GWAS platforms [47-49]. As technological advances and declining costs in next-generation sequencing technologies pave the way for the broader availability of genomic testing, the implementation of genetic susceptibility data will help to improve risk stratification and to reduce the incidence and sequelae of cardiac surgery [50].

\section{Conclusions}

In the setting of cardiac surgery, we identified the MIF promotor polymorphisms CATT 7 (rs3063368) and -270 (formerly -173) G>C (rs755622), to be predictive of development of postoperative AKI and death. These MIF promoter alleles could improve current clinical risk prediction models and thus serve as a helpful decision-making tool for clinicians and patients in the near future.

Supplementary Materials: The following are available online at http://www.mdpi.com/2077-0383/9/9/2936/s1. Supplemental Figure S1. Flowchart of the patients screened and included in the study. Supplemental Figure S2. SNP rs5844572 region $\left(\mathrm{CATT}_{\mathrm{n}}\right.$ tetranucleotide repeat) and $\mathrm{rs} 755622(\mathrm{G}>\mathrm{C}$ ) with UCSC genome browser (Geb. 2009; GRCh37/hg19 Assembly). Supplemental Table S1. Primer sequences used for genotyping of the tetranucleotide repeat polymorphism CATT $\mathrm{n}$ (rs3063368). Supplemental Table S2. Association of MIF promoter polymorphisms with Myocardial Infarction. Supplemental Table S3. Association of MIF promoter polymorphisms with Stroke. Supplemental Table S4. Association of MIF promoter polymorphisms with delir. Supplemental Table S5. Association of MIF regulatory polymorphisms with atrial fibrillation.

Author Contributions: Conceptualization, L.A., C.S. and K.Z.; Methodology, L.A., C.S., K.F.; Software, K.F., C.S.; Validation, K.F., L.A., C.S., Formal Analysis, K.F., L.A., C.S., J.B.; Investigation, L.A., K.F., S.M., C.S.; Resources, C.S., K.Z., R.B., J.B., G.M.; Data Curation, K.F., L.A.; Writing-Original Draft Preparation, L.A., C.S.; Writing-Review and Editing, J.B., R.B., H.S., H.-J.L., S.M., P.M., D.W., L.L., G.M., D.E.L., A.Z.; Project Administration, C.S.; Funding Acquisition, C.S., K.Z., J.B. All authors have read and agreed to the published version of the manuscript.

Funding: This study was partly supported by the Deutsche Forschungsgemeinschaft (DFG; STO 1099/8-1 to CS BE 1977/9-1; BE 1977/14-1 to JB; SFB1123/A3 to JB). The RIPHeart Study was funded by the German Research Foundation (ME 3559/1-1).

Acknowledgments: We are thankful for the technical support received from Christian Beckers. RIPHeart Study Collaborators: Ana Stevanovic, Rolf Rossaint, Marc Felzen, Andreas Goetzenich, Tobias Moormann, Katharina Chalk, Pascal Knuefermann, Thomas Recht, Andreas Hoeft, Michael Winterhalter, Sonja Iken, Carolin Wiedenbeck, Gerhard Schwarzmann, Simone Lindau, Andreas Zierer, Stephan Fichtlscherer, Gerold Goerlach, Matthias Wollbrueck, Ursula Boening, Markus Weigand, Julia Strauchmann, Kai U. Morsbach, Markus Paxian, Konrad Reinhard, Jens Scholz, Jochen Renner, Ole Broch, Helga Francksen, Bernd Kuhr, Hermann Heinze, Hauke Paarmann, Hans-Hinrich Sievers, Stefan Klotz, Thomas Hachenberg, Christian Werner, Susanne Mauff, Angela Alms, Stefan Bergt, and Norbert Roewer. Aachen (Department of Anesthesiology, Medical Faculty RWTH Aachen University, Aachen, Germany): Ana Stevanovic, Rolf Rossaint, Marc Felzen, (Department of Thoracic and Cardiovascular Surgery): Andreas Goetzenich; 195 patients; Berlin (Department of Anesthesiology and Intensive Care Medicine, Charité-Universitätsmedizin Berlin, Campus Charité Mitte, Berlin, Germany): Tobias Moormann, Katharina Chalk; 37 patients; Bonn (Department of Anesthesiology and Intensive Care Medicine, University Hospital Bonn, Bonn, Germany): Pascal Knuefermann, Thomas Recht, Andreas Hoeft; 73 patients; Duesseldorf (Department of Anesthesiology and Intensive Care Medicine, University Hospital Duesseldorf, Germany): Michael Winterhalter; 65 patients; Frankfurt am Main (Department of Anesthesiology, Intensive Care Medicine and Pain Therapy, University Hospital Frankfurt, Frankfurt am Main, Germany): Sonja Iken, Carolin Wiedenbeck, Gerhard Schwarzmann, Simone Lindau, (Department of Thoracic and Cardiovascular Surgery): Andreas Zierer, (Internal Medicine III: Cardiology, Angiology, Nephrology): Stephan Fichtlscherer; 117 patients; Giessen (Department of Cardiovascular Surgery, University of Giessen, Germany): Gerold Goerlach, 
Matthias Wollbrueck, Ursula Boening; (Department of Anesthesiology): Markus Weigand; 148 patients; Goettingen (Department of Anesthesiology and Intensive Care Medicine, University Hospital Goettingen, Germany): Julia Strauchmann, Konrad August; 91 patients; Jena (Department of Anesthesiology and Intensive Care Medicine, Jena University Hospital, Jena, Germany): Kai U. Morsbach, Markus Paxian, Konrad Reinhard; 76 patients; Kiel (Department of Anesthesiology and Intensive Care Medicine, University Hospital Schleswig-Holstein, Campus Kiel, Germany): Jens Scholz, Jochen Renner, Ole Broch, Helga Francksen, Bernd Kuhr; 237 patients; Luebeck (Department of Anesthesiology, University Hospital Luebeck, Luebeck, Germany): Hermann Heinze, Hauke Paarmann; (Department of Cardiac and Thoracic Vascular Surgery): Hans-Hinrich Sievers, Stefan Klotz; 56 patients; Magdeburg (Department of Anesthesiology, University Hospital Magdeburg, Germany); Thomas Hachenberg; 14 patients; Mainz (Department of Anesthesiology, Medical Center of Johannes Gutenberg-University, Mainz, Germany): Christian Werner, Susanne Mauff; 116 patients; Rostock (Clinic of Anesthesiology and Intensive Care Medicine, University Hospital Rostock, Rostock, Germany): Angela Alms, Stefan Bergt; 146 patients; Wuerzburg (Department of Anesthesiology, University Hospital Wuerzburg, Wuerzburg, Germany): Norbert Roewer; 32 patients.

Conflicts of Interest: R.B. has significant financial interests. He is a co-inventor on patents related to therapeutic MIF modulation and MIF genotyping, and owns more than $5 \%$ of the voting shares in MIFCOR, Inc, a Yale University biotechnology start-up company. J.B. is a co-inventor on patents describing the therapeutic utility of MIF antagonists (modest interests). D.E.L. has received research grant support from BioPorto Diagnostics (modest interests). R.B., J.B., and D.E.L. did not shape or manipulate the design and execution of the study. They contributed by helping with interpretation of data and by reviewing the manuscript.

\section{References}

1. Brown, P.P.; Kugelmass, A.D.; Cohen, D.J.; Reynolds, M.R.; Culler, S.D.; Dee, A.D.; Simon, A.W. The Frequency and Cost of Complications Associated with Coronary Artery Bypass Grafting Surgery: Results from the United States Medicare Program. Ann. Thorac. Surg. 2008, 85, 1980-1986. [CrossRef]

2. Grover, A.; Gorman, K.; Dall, T.M.; Jonas, R.; Lytle, B.; Shemin, R.; Wood, D.; Kron, I. Shortage of Cardiothoracic Surgeons Is Likely by 2020. Circulation 2009, 120, 488-494. [CrossRef] [PubMed]

3. Roques, F.; Nashef, S.A.; Michel, P.; Gauducheau, E.; De Vincentiis, C.; Baudet, E.; Cortina, J.; David, M.; Faichney, A.; Gavrielle, F.; et al. Risk factors and outcome in European cardiac surgery: Analysis of the EuroSCORE multinational database of 19030 patients. Eur. J. Cardio-Thorac. Surg. 1999, 15, 816-823. [CrossRef]

4. Sureshbabu, A.; Ryter, S.W.; Choi, M.E. Oxidative stress and autophagy: Crucial modulators of kidney injury. Redox Biol. 2015, 4, 208-214. [CrossRef] [PubMed]

5. Stoppe, C.; Rex, S.; Goetzenich, A.; Kraemer, S.; Emontzpohl, C.; Soppert, J.; Averdunk, L.; Sun, Y.; Rossaint, R.; Lue, H.; et al. Interaction of MIF Family Proteins in Myocardial Ischemia/Reperfusion Damage and Their Influence on Clinical Outcome of Cardiac Surgery Patients. Antioxid. Redox Signal. 2015, 23, 865-879. [CrossRef] [PubMed]

6. Ozsoy, A.Z.; Karakus, N.; Tural, S.; Yigit, S.; Kara, N.; Alaylı, G.; Tumer, M.K.; Kuru, O. Influence of the MIF polymorphism $-173 \mathrm{G}>\mathrm{C}$ on Turkish postmenopausal women with osteoporosis. Z. Rheumatol. 2017, 77, 629-632. [CrossRef] [PubMed]

7. Vishwakarma, S.K.; Lakkireddy, C.; Sravani, G.; Sastry, B.V.S.; Raju, N.; Ahmed, S.I.; Owaisi, N.; Jaisawal, A.; Khan, M.A.; Khan, A.A. Association of CD14 and macrophage migration inhibitory factor gene polymorphisms with inflammatory microRNAs expression levels in ankylosing spondylitis and polyarthralgia. Int. J. Immunogenet. 2018, 45, 190-200. [CrossRef]

8. Benedek, G.; Meza-Romero, R.; Jordan, K.; Zhang, Y.; Nguyen, H.; Kent, G.; Li, J.; Siu, E.; Frazer, J.; Piecychna, M.; et al. MIF and D-DT are potential disease severity modifiers in male MS subjects. Proc. Natl. Acad. Sci. USA 2017, 114, E8421-E8429. [CrossRef]

9. Bae, S.-C.; Lee, Y.H. Circulating macrophage migration inhibitory factor levels and its polymorphisms in systemic lupus erythematosus: A meta-analysis. Cell. Mol. Biol. 2017, 63, 74-79. [CrossRef]

10. Baugh, J.A.; Chitnis, S.; Donnelly, S.C.; Monteiro, J.; Lin, X.; Plant, B.J.; Wolfe, F.; Gregersen, P.K.; Bucala, R. A functional promoter polymorphism in the macrophage migration inhibitory factor (MIF) gene associated with disease severity in rheumatoid arthritis. Genes Immun. 2002, 3, 170-176. [CrossRef]

11. Yao, J.; Leng, L.; Sauler, M.; Fu, W.-L.; Zheng, J.; Zhang, Y.; Du, X.; Yu, X.; Lee, P.; Bucala, R. Transcription factor ICBP90 regulates the MIF promoter and immune susceptibility locus. J. Clin. Investig. 2016, 126, 732-744. [CrossRef] [PubMed] 
12. Guo, P.; Wang, J.; Liu, J.; Xia, M.; Li, W.; He, M. Macrophage immigration inhibitory factor promotes cell proliferation and inhibits apoptosis of cervical adenocarcinoma. Tumor Biol. 2015, 36, 5095-5102. [CrossRef] [PubMed]

13. Meybohm, P.; Bein, B.; Brosteanu, O.; Cremer, J.T.; Gruenewald, M.; Stoppe, C.; Coburn, M.; Schaelte, G.; Böning, A.; Niemann, B.; et al. A Multicenter Trial of Remote Ischemic Preconditioning for Heart Surgery. N. Engl. J. Med. 2015, 373, 1397-1407. [CrossRef] [PubMed]

14. Sreih, A.; Ezzeddine, R.; Leng, L.; Lachance, A.; Yu, G.; Mizuec, Y.; Subrahmanyan, L.; Pons-Estel, B.A.; Abelson, A.-K.; Gunnarsson, I.; et al. Dual effect of the macrophage migration inhibitory factor gene on the development and severity of human systemic lupus erythematosus. Arthritis Rheum. 2011, 63, 3942-3951. [CrossRef]

15. Palevsky, P.M.; Liu, K.D.; Brophy, P.D.; Chawla, L.S.; Parikh, C.R.; Thakar, C.V.; Tolwani, A.J.; Waikar, S.S.; Weisbord, S.D. KDOQI US Commentary on the 2012 KDIGO Clinical Practice Guideline for Acute Kidney Injury. Am. J. Kidney Dis. 2013, 61, 649-672. [CrossRef]

16. Thygesen, K.; Alpert, J.S.; White, H.D.; Jaffe, A.S.; Apple, F.S.; Galvani, M.; Katus, H.A.; Newby, L.K.; Jan, R.; Chaitman, B.; et al. Universal Definition of Myocardial Infarction. Circulation 2007, 116, $2634-2653$. [CrossRef]

17. Ely, E.W.; Inouye, S.K.; Bernard, G.R.; Gordon, S.; Francis, J.; May, L.; Truman, B.; Speroff, T.; Gautam, S.; Margolin, R.; et al. Delirium in mechanically ventilated patients: Validity and reliability of the confusion assessment method for the intensive care unit (CAM-ICU). JAMA 2001, 286, 2703-2710. [CrossRef] [PubMed]

18. Wityk, R.J.; Pessin, M.S.; Kaplan, R.F.; Caplan, L.R. Serial assessment of acute stroke using the NIH Stroke Scale. Stroke 1994, 25, 362-365. [CrossRef]

19. Harris, J.; Morand, E.F. Macrophage Migration Inhibitory Factor Methods and Protocols; Methods in Molecular Biology; Springer: Berlin, Germany, 2020; Volume 2080.

20. Karczewski, K.J.; Francioli, L.C.; Tiao, G.; Cummings, B.B.; Alfoldi, J.; Wang, Q.; Collins, R.L.; Laricchia, K.M.; Ganna, A.; Birnbaum, D.P.; et al. The mutational constraint spectrum quantified from variation in 141,456 humans. Nature 2020, 581, 434-443. [CrossRef]

21. Bacher, M.; Meinhardt, A.; Lan, H.Y.; Mu, W.; Metz, C.N.; Chesney, J.A.; Calandra, T.; Gemsa, D.; Donnelly, T.; Atkins, R.C.; et al. Migration inhibitory factor expression in experimentally induced endotoxemia. Am. J. Pathol. 1997, 150, 235-246.

22. Gando, S.; Nishihira, J.; Kemmotsu, O.; Kobayashi, S.; Morimoto, Y.; Matsui, Y.; Yasuda, K. An increase in macrophage migration inhibitory factor release in patients with cardiopulmonary bypass surgery. Surg. Today 2000, 30, 689-694. [CrossRef] [PubMed]

23. Stoppe, C.; Averdunk, L.; Goetzenich, A.; Soppert, J.; Marlier, A.; Kraemer, S.; Vieten, J.; Coburn, M.; Kowark, A.; Kim, B.-S.; et al. The protective role of macrophage migration inhibitory factor in acute kidney injury after cardiac surgery. Sci. Transl. Med. 2018, 10, aan4886. [CrossRef]

24. Stoppe, C.; Grieb, G.; Rossaint, R.; Simons, D.; Coburn, M.; Götzenich, A.; Strüssmann, T.; Pallua, N.; Bernhagen, J.; Rex, S. High Postoperative Blood Levels of Macrophage Migration Inhibitory Factor Are Associated with Less Organ Dysfunction in Patients after Cardiac Surgery. Mol. Med. 2012, 18, 843-850. [CrossRef] [PubMed]

25. Liu, A.; Bao, F.; Voravuthikunchai, S.P. CATT polymorphism in MIF gene promoter is closely related to human pulmonary tuberculosis in a southwestern China population. Int. J. Immunopathol. Pharmacol. 2018, 32. [CrossRef] [PubMed]

26. Valdes-Alvarado, E.; Muñoz-Valle, J.F.; Valle, Y.; Sandoval-Pinto, E.; García-González, I.J.; Valdez-Haro, A.; De La Cruz-Mosso, U.; Flores-Salinas, H.E.; Padilla-Gutierrez, J.R. Association between the -794 (CATT)5-8 MIF Gene Polymorphism and Susceptibility to Acute Coronary Syndrome in a Western Mexican Population. J. Immunol. Res. 2014, 2014, 704854. [CrossRef] [PubMed]

27. Lan, M.-Y.; Chang, Y.-Y.; Chen, W.-H.; Tseng, Y.-L.; Lin, H.-S.; Lai, S.-L.; Liu, J.-S. Association between MIF gene polymorphisms and carotid artery atherosclerosis. Biochem. Biophys. Res. Commun. 2013, 435, 319-322. [CrossRef] [PubMed]

28. Sanchez, E.; Gómez, L.M.; Lopez-Nevot, M.A.; González-Gay, M.A.; Sabio, J.M.; Ortego-Centeno, N.; De Ramón, E.; Anaya, J.; González-Escribano, M.F.; Koeleman, B.P.; et al. Evidence of association of macrophage migration inhibitory factor gene polymorphisms with systemic lupus erythematosus. Genes Immun. 2006, 7, 433-436. [CrossRef] 
29. Mitchell, R.A.; Liao, H.; Chesney, J.; Fingerle-Rowson, G.; Baugh, J.; David, J.; Bucala, R. Macrophage migration inhibitory factor (MIF) sustains macrophage proinflammatory function by inhibiting p53: Regulatory role in the innate immune response. Proc. Natl. Acad. Sci. USA 2001, 99, 345-350. [CrossRef]

30. Qian, L.; Wang, X.-Y.; Thapa, S.; Tao, L.-Y.; Wu, S.-Z.; Luo, G.-J.; Wang, L.-P.; Wang, J.-N.; Wang, J.; Li, J.; et al. Macrophage migration inhibitory factor promoter polymorphisms (-794 CATT5-8): Relationship with soluble MIF levels in coronary atherosclerotic disease subjects. BMC Cardiovasc. Disord. 2017, 17, 144. [CrossRef]

31. Payen, D.; Lukaszewicz, A.-C.; Legrand, M.; Gayat, E.; Faivre, V.; Mégarbane, B.; Azoulay, E.; Fieux, F.; Charron, D.; Loiseau, P.; et al. A Multicentre Study of Acute Kidney Injury in Severe Sepsis and Septic Shock: Association with Inflammatory Phenotype and HLA Genotype. PLoS ONE 2012, 7, e35838. [CrossRef]

32. Baron-Stefaniak, J.; Schiefer, J.; Miller, E.J.; Berlakovich, G.A.; Baron, D.M.; Faybik, P. Comparison of macrophage migration inhibitory factor and neutrophil gelatinase-associated lipocalin-2 to predict acute kidney injury after liver transplantation: An observational pilot study. PLoS ONE 2017, 12, e0183162. [CrossRef] [PubMed]

33. Brown, F.G.; Nikolic-Paterson, D.J.; Hill, P.A.; Isbel, N.M.; Dowling, J.; Metz, C.M.; Atkins, R.C. Urine macrophage migration inhibitory factor reflects the severity of renal injury in human glomerulonephritis. J. Am. Soc. Nephrol. 2002, 13, S7-S13. [PubMed]

34. Brown, F.G.; Nikolic-Paterson, D.J.; Chadban, S.J.; Dowling, J.; Jose, M.D.; Metz, C.N.; Bucala, R.; Atkins, R.C. Urine Macrophage Migration Inhibitory Factor Concentrations as a Diagnostic Tool in Human Renal Allograft Rejection. Transplantion 2001, 71, 1777-1783. [CrossRef] [PubMed]

35. Djudjaj, S.; Martin, I.V.; Buhl, E.M.; Nothofer, N.J.; Leng, L.; Piecychna, M.; Floege, J.; Bernhagen, J.; Bucala, R.; Boor, P. Macrophage Migration Inhibitory Factor Limits Renal Inflammation and Fibrosis by Counteracting Tubular Cell Cycle Arrest. J. Am. Soc. Nephrol. 2017, 28, 3590-3604. [CrossRef]

36. Herder, C.; Illig, T.; Baumert, J.; Müller-Nurasyid, M.; Klopp, N.; Khuseyinova, N.; Meisinger, C.; Martin, S.; Thorand, B.; Koenig, W. Macrophage migration inhibitory factor (MIF) and risk for coronary heart disease: Results from the MONICA/KORA Augsburg case-cohort study, 1984-2002. Atherosclerosis 2008, 200, 380-388. [CrossRef]

37. Tong, X.; He, J.; Liu, S.; Peng, S.; Yan, Z.; Zhang, Y.; Fan, H. Macrophage migration inhibitory factor -173G/C gene polymorphism increases the risk of renal disease: A meta-analysis. Nephrology 2015, 20, 68-76. [CrossRef]

38. Bruchfeld, A.; Carrero, J.J.; Qureshi, A.R.; Lindholm, B.; Bárány, P.; Heimburger, O.; Hu, M.; Lin, X.; Stenvinkel, P.; Miller, E.J. Elevated Serum Macrophage Migration Inhibitory Factor (MIF) Concentrations in Chronic Kidney Disease (CKD) Are Associated with Markers of Oxidative Stress and Endothelial Activation. Mol. Med. 2009, 15, 70-75. [CrossRef]

39. Chawla, L.S.; Kimmel, P.L. Acute kidney injury and chronic kidney disease: An integrated clinical syndrome. Kidney Int. 2012, 82, 516-524. [CrossRef]

40. Rassaf, T.; Weber, C.; Bernhagen, J. Macrophage migration inhibitory factor in myocardial ischaemia/reperfusion injury. Cardiovasc. Res. 2014, 102, 321-328. [CrossRef]

41. Tilstam, P.V.; Qi, D.; Leng, L.; Young, L.; Bucala, R. MIF family cytokines in cardiovascular diseases and prospects for precision-based therapeutics. Expert Opin. Ther. Targets 2017, 21, 671-683. [CrossRef]

42. Yoo, S.-A.; Leng, L.; Kim, B.-J.; Du, X.; Tilstam, P.V.; Kim, K.H.; Kong, J.-S.; Yoon, H.-J.; Liu, A.; Wang, T.; et al. MIF allele-dependent regulation of the MIF coreceptor CD44 and role in rheumatoid arthritis. Proc. Natl. Acad. Sci. USA 2016, 113, E7917-E7926. [CrossRef] [PubMed]

43. Ochi, A.; Chen, N.; Schulte, W.; Leng, L.; Moeckel, N.G.; Piecychna, M.; Averdunk, L.; Stoppe, C.; Bucala, R.; Moeckel, G.W. MIF-2/D-DT enhances proximal tubular cell regeneration through SLPI- and ATF4-dependent mechanisms. Am. J. Physiol. Physiol. 2017, 313, F767-F780. [CrossRef] [PubMed]

44. Herder, C.; Klopp, N.; Baumert, J.; Müller-Nurasyid, M.; Khuseyinova, N.; Meisinger, C.; Martin, S.; Illig, T.; Koenig, W.; Thorand, B. Effect of macrophage migration inhibitory factor (MIF) gene variants and MIF serum concentrations on the risk of type 2 diabetes: Results from the MONICA/KORA Augsburg Case-Cohort Study, 1984-2002. Diabetologia 2007, 51, 276-284. [CrossRef] [PubMed]

45. Matia-García, I.; Salgado-Goytia, L.; Muñoz-Valle, J.F.; García-Arellano, S.; Hernández-Bello, J.; Salgado-Bernabé, A.B.; Parra-Rojas, I. Macrophage Migration Inhibitory Factor Promoter Polymorphisms (-794 CATT5-8and -173 G > C): Relationship with mRNA Expression and Soluble MIF Levels in Young Obese Subjects. Dis. Markers 2015, 2015, 461208. [CrossRef] [PubMed] 
46. Zhong, X.-B.; Leng, L.; Beitin, A.; Chen, R.; McDonald, C.; Hsiao, B.; Jenison, R.D.; Kang, I.; Park, S.-H.; Lee, A.; et al. Simultaneous detection of microsatellite repeats and SNPs in the macrophage migration inhibitory factor (MIF) gene by thin-film biosensor chips and application to rural field studies. Nucleic Acids Res. 2005, 33, e121. [CrossRef]

47. Westphal, S.; Stoppe, C.; Gruenewald, M.; Bein, B.; Renner, J.; Cremer, J.; Coburn, M.; Schälte, G.; Boening, A.; Niemann, B.; et al. Genome-wide association study of myocardial infarction, atrial fibrillation, acute stroke, acute kidney injury and delirium after cardiac surgery-A sub-analysis of the RIPHeart-Study. BMC Cardiovasc. Disord. 2019, 19, 26. [CrossRef]

48. Saw, K.M.E.; Ng, R.G.R.; Chan, S.P.; Ang, Y.H.; Ti, L.K.; Chew, T.H.S. Association of genetic polymorphisms with acute kidney injury after cardiac surgery in a Southeast Asian population. PLoS ONE 2019, 14, e0213997. [CrossRef]

49. Leaf, D.E.; Body, S.C.; Muehlschlegel, J.D.; McMahon, G.M.; Lichtner, P.; Collard, C.D.; Shernan, S.K.; Fox, A.A.; Waikar, S.S. Length Polymorphisms in Heme Oxygenase-1 and AKI after Cardiac Surgery. J. Am. Soc. Nephrol. 2016, 27, 3291-3297. [CrossRef]

50. Suwinski, P.; Ong, C.; Ling, M.H.T.; Poh, Y.M.; Khan, A.M.; Ong, H.S. Advancing Personalized Medicine Through the Application of Whole Exome Sequencing and Big Data Analytics. Front. Genet. 2019, 10, 49. [CrossRef]

(C) 2020 by the authors. Licensee MDPI, Basel, Switzerland. This article is an open access article distributed under the terms and conditions of the Creative Commons Attribution (CC BY) license (http://creativecommons.org/licenses/by/4.0/). 